\title{
Mathematical model of risk management of stakeholders of wind power projects
}

\author{
A. V. Sevostianova \\ National Transport University, Kyiv, Ukraine \\ Corresponding author. E-mail: Sevostianova1607@gmail.com
}

Paper received 14.11.19; Accepted for publication 28.11.19.

\section{https://doi.org/10.31174/SEND-HS2019-214VII36-07}

\begin{abstract}
Conducting a glance at the most important approaches to managing stakeholders of the wind power projects and evaluation of the risks of such projects. In this article mathematically described the possible systems of interoperability and the threat of stakeholders of the wind power projects, for the more significant balance of risks for skin stakeholders in energy technology projects. It is marked that according to the system of interoperability and the threat of stakeholders wind power projects, all stakeholders can be divided into three groups: threatened, harmonized and chances.
\end{abstract}

Keywords: wind power project; risk management; stakeholders.

Introduction. Wind power is an important sector both for Ukraine and for the world, its development will reduce dependence on imported fuel and harmful emissions of greenhouse gases and other environmental pollution. In addition, the European Commission attributed wind power to one of the priority areas for the development of electricity generation in the world, and according to the International Energy Agency, the share of wind power in global electricity production will increase to $40 \%$, and wind power stations will be the cheapest way of electricity generation in most countries [1].

The uniqueness of the products of the wind power industry and wind power enterprises, the presence of clearly defined goals and limitations in its design and production allow us to consider the processes of design and production of such products in terms of project management theory and practice. And to make positive projections requires proper and skillful management, which takes into account the specific features of such projects and aims to improve their effectiveness.

Wind power projects are projects aimed at creating such a product as electricity through the use of wind power [1], they are targeted, unique and have their own peculiarities, which are: geographical location and influence of the natural features of the location regions; renewability of wind energy sources; the high cost of wind turbines and additional electrical appliances; the peculiarities of technological processes that are associated with the inability to store energy on a large scale and the need for uninterrupted power supply, which is highly dependent on the manufacturer, supplier, consumer, etc.; a large number of organizations involved in projects and social components; environmental friendliness of wind farms; high investment attractiveness, average payback and more. Management of WPP has its own specificity, in particular: innovation and complexity of production and technical equipment of WPP; the multiplicity of projects and their scope; the need to support the intensification of the introduction of foreign capital and the development of new forms of international cooperation; high requirements for maneuvering generating installations and ensuring balancing with the environment; strategic focus on energy and environmental security; the use of a variety of different mechanisms and methods of managing WPP; the need to manage the risks of WPP related to large project teams, the activity of socio-political and public organizations to management facilities, their interaction, etc., besides, there is a serious dependence of such management on a large number of stakeholders, starting with investors and politicians and non-governmental organizations and the nearby population.

Each stakeholder, on the one hand, has a positive impact that opens up the chances of a WPP, and on the other hand, it can have a negative impact that causes or leads to risks. Existing uncertainties and disagreements result in high risks associated with WPP stakeholders, which threaten the implementation and effectiveness of such projects.

A brief overview of publications on the topic. Modern project management methodology considers project risks from the perspective of different approaches. In this direction are known works of foreign and domestic scientists: Drucker Peter F., JM Keynes, G. Simon, Tovby AS, Tsipesa GL, Shapiro VD, Voropayeva VI, Burkova VM, Druzhinina EA etc. Researchers in the activity of enterprises in the context of project management and risk management have worked on domestic scientists: Bushuev, Yu.M. Tesla, S.K. Chernov, KV Koshkin, V.A. Rach, E.A. Druzhinin, OB Danchenko, Yu.M. Kharitonov, IB Semko et al. Problem issues in the field of wind power, its advantages and disadvantages are discussed in the source [1], methods and means of risk management of alternative energy projects in [2-3]. The analysis of the basic methods of project management in the field of wind power is carried out in [4], information and mathematical methods of resource management in the development of projects of the wind power enterprise is carried out in [5]. Two extreme positions of riskology, as "chance management" and "risk management", are considered in the source [6]. Stakeholder management within frameworks of project management is presented in the international standard $\mathrm{PMBOK}$ [7] and national standard ICB 4.0 [8], which defines the competencies for professionals involved in project management, programs and portfolios. ISO 26000: 2010 Guidance on social responsibility includes guidance on corporate social responsibility. The ISO 21500: 2012 "Project Management Guide" in the section "Stakeholders and Organizational Structure" describes the specific stakeholders for the project. International standard AA1000 Stakeholder Engagement Standard 2018 is a standard regulatory framework for planning, executing, 
evaluating, informing and non-financial auditing the quality of stakeholder engagement in the reporting and accountability processes of organizations. It contains a complete step-by-step guide on how to involve stakeholders in the processes of the company, defines recommendations for the formation of social reporting of organizations. The main feature of this approach, which sets it apart from others, is the application of the method of business dialogue with stakeholders. According to sourse [9], there are two approaches to stakeholder management: a partnership approach and a method of protection, O.M. Medvedeva considers a method of systematically integrated stakeholder activity modeling for interaction management tasks (based on project activity), and stakeholder activity modeling based on projects integrated cognitive map of the interaction environment. Sourse [10] conducted a dynamic analysis of project stakeholders' methods and tools, demonstrated the need to improve quantitative project stakeholder analysis methods and their requirements, noted the presence of two stakeholder theory schools: the first focused on stakeholder management, with a view to eliminating them the goals of the project, and insists that the success of the project depends on all stakeholders, the second - focuses on human relations within the stakeholder management and insists on managing interactions between different parties. Risk management in projects in the contextual and behavioral uncertainty investigated by D.V. Rach. According to sourse [1] project risk is an unspecified event or condition that has a negative or positive effect on project goals, such as content, schedule, cost and quality, and the objectives of project risk management are to increase the likelihood of occurrence and increase the impact of favorable events and reduce the likelihood of adverse events. Risk can also be measured by combining the likelihood of a threat / opportunity and the magnitude of their impact on targets [11]. The harmonization of interests of shareholders of corporations and other stakeholders in terms of entry into international markets is considered in [12].

An analysis of the literature materials shows that the existing mathematical apparatus is imperfect and does not take into account the specifics of managing the WPP stakeholders on the basis of a risk-free approach. Therefore, the research and modernization of the risk management of WPP stakeholders is urgent, which needs to be specified and optimized.

The purpose of the article is to develop a mathematical model of risk management for wind energy projects stakeholders, which allows them to assess their opportunities and threats, determine the magnitudes of risk balances, evaluate the stakeholders on these balances and to form a set of stakeholders in accordance with their balance sheets.

Outline of the main material and results of the study. Each stakeholder group has its own influence on the project. The impact can be positive (chance), negative (threatening) or neutral [13]. The positive impact of stakeholders on the implementation of WPP is beneficial because it helps to implement the project. However, it can have negative consequences. In general, a negative impact is not beneficial during the project implementation. However, sometimes it can be the other way around.
Neutral impact generally does not affect the implementation of the project in any way, however, sometimes it can be altered by external factors and then from neutral to either positive or negative. It is important for the project manager and the project team not to overlook the neutral impact as a negative one, or to make an effort to change the neutral position to a positive one.

Based on the conceptual model of balance of risks (opportunities and threats) of the stakeholders of wind power projects, which is described in source [13], due to their opposite of opportunity and threat, being antipolar, they mutually oppose and limit each other. When one side is in excess, the other is lacking. As one side weakens, the other becomes stronger. To ensure effective management of WPP stakeholders, it is necessary to balance their risks: to increase the opportunities for positive impact of participants and to reduce the possibility of threats, while maintaining the stable state of the system, within the three categories that correspond to the magic triangle of project management goals: duration, cost, quality that is possible by combining techniques of opportunity management (chance management) and threats (risk management).

The anti-lingual management of WPP stake holders includes eight steps (Fig. 1).

\begin{tabular}{|c|c|}
\hline & - Determination of the set of WPP stakeholders. \\
\hline 2 & $\begin{array}{l}\text { - Determining the multitude of opportunities for WPP } \\
\text { stakeholders. }\end{array}$ \\
\hline & •Identifying the multiple threats of WPP stakeholders. \\
\hline & •Assessment of opportunities for WPP stakeholders. \\
\hline t & $\begin{array}{l}\text { - Estimation of the magnitude of the threats of } \\
\text { WPPstakeholders. }\end{array}$ \\
\hline & - Determination of risk balances for WPP stakeholders. \\
\hline & - Holding a stakeholder rating on the balance of their risks. \\
\hline & - Making a regulatory decision. \\
\hline
\end{tabular}

Figure 1. Stages of risk management of WPP Stakeholders

We use a mathematical apparatus, in particular: methods of set theory, system analysis, etc., to describe the possible states of the system of interaction between the opportunities and threats of WPP stakeholders.

First, set the number of WPPs stakholders, S (Stakholders):

$$
S=\left\{S_{1} ; \ldots ; S_{k} ; \ldots ; S_{l}\right\}
$$

where $l$ - the number of WPP stakeholders,

$k$ - number of stakeholder, $(k=\overline{1 ; l})$.

Based on the conceptual model of the balance of risks (opportunities and threats) of WPP stakeholders, outlined in the sourse [13], to ensure effective management of WPP stakeholders, it is necessary to balance their risks: to increase the opportunities of positive influence of participants and to reduce the chances of occurrence of threats. Therefore, it is first and foremost necessary to identify opportunities and threats.

Let us denote the set of possibilities for WPP stakeholders as $C$ (Chance):

$$
\mathrm{C}_{k}=\left\{\mathrm{C}_{k 1} ; \ldots ; \mathrm{C}_{k i ; \ldots} ; \mathrm{C}_{k n}\right\}
$$

where $C_{k i}$ - the opportunities of a $k$-th stakeholder of WPP; $n-$ number of stakeholde's opportunities, $i$-number of the opportunity $k-t h$ stakeholder , $(i=$ $\overline{1 ; n})$. 
The possibility of a $k$-th stakeholder of WPP $C_{k i}$ can be written by the formula:

$$
C_{k i}=\sum_{i=1}^{n} P_{k i} \cdot V_{k i},
$$

where $P_{k i}$-the probability of the occurrence $i$ - th opportunities for a WPP stakeholder; $V_{k i}$ - the gain from the $i$ - th opportunities, uah, $n$ - number of stakeholde's opportunities.

We denote the set of the threats to WPP stakeholders as $D$ (Danger):

$$
D_{k}=\left\{D_{k 1} ; \ldots ; D_{k j ; . . ;} ; D_{k m}\right\},
$$

where $D_{k j}-a$ threat of $k$-th WPP stakeholder, $m$ - the number of stakeholder threats, $\mathrm{j}$ is the number of the opportunity of $k$-th stakeholder, $(j=\overline{1 ; m})$.

Threats of $k$ - th WPP stakeholder $D_{k j} \quad$ can be written by the formula:

$$
D_{k j}=\sum_{j=1}^{m} P_{k j} \cdot V_{k j}
$$

where $P_{k j}$ - the probability of occurrence of the $j$-th threat; $V_{k j}$ - losses from the $j$-th threat, uah., $m-$ the number of stakeholder threats.

We designate the set of the risks (opportunities and threats) of WPP as $B R$ (Balance of risk):

$$
B R=\left\{B R_{1} ; \ldots ; B R_{k} ; \ldots ; B R_{l}\right\},
$$

where $B R_{k}$ - the balance of risk for $k$-th WPP stakeholder, $l$ - WPP stakeholder's number, $k$ stakeholder number, $(k=\overline{1 ; l})$.

Based on the conceptual model of risk balance (opportunities and threats), the WPP stakeholders hold the magnitude of the risk balance $B R_{k}$ for $k$-th stakeholder WPP can be written by the formula:

$$
B R_{k}=\sum_{\mathrm{i}=1}^{\mathrm{n}} C_{k i}+\sum_{\mathrm{j}=1}^{\mathrm{m}} D_{k j},
$$

Based on formula (3) and formula (5), the magnitude of the risk balance $B R_{k}$ for the $k$-th WPP stakeholder will be expressed:

$$
B R_{k}=\sum_{i=1}^{n} P_{k i} \cdot V_{k i}+\sum_{j=1}^{m} P_{k j} \cdot V_{k j}
$$

Considering the possible states of the system of interaction of opportunities and threats of WPP stakeholders [14], the magnitude of the risk balance $\left(B R_{k}\right)$ for the $k$-th stakeholder may take the following values:

$$
B R_{k}=\left\{\begin{array}{l}
B R_{k}<0, \text { if } C_{k}<D_{k} \\
B R_{k}=0, \text { if } C_{k}=D_{k} \\
B R_{k}>0, \text { if } C_{k}>D_{k},
\end{array}\right.
$$

where $C_{k}$ - the total value of the capabilities of the $k$-th WPP stakeholder, and $D_{k}$-the total magnitude of the threats of the k-th WPP stakeholder.

According to the conceptual model of balance of risks (opportunities and threats) [13], all WPP stakeholders are divided into three groups:

- at $B R_{k}<0$ - threatening, in which high threats and low opportunities;
- at $B R_{k}=0$ - harmonized, where opportunities and threats are in equilibrium;

- at $B R_{k}>0$-chances that have high opportunities and low threats.

Based on the results obtained, it is possible to identify appropriate sets of stakeholders and to evaluate the stakeholders on the balance of their risks (opportunities and threats).

That is, the set of WPP stakeholders, $\mathrm{S}$, can be represented by the formula:

$$
S=\left\{S_{D}\right\} \cup\left\{S_{G}\right\} \cup\left\{S_{C}\right\},
$$

where $S_{D}$ - set of the threatening WPP stakeholders; $S_{G}$ - a set of harmonized WPP stakeholders; $S_{C}-$ a set of chancable WPP stakeholders.

For each set of WPP stakeholders, additional assessments of opportunities and threats within the set can be made, or for each stakeholder individually, using a stakeholder matrix, which allows thoroughly investigate risk components (opportunities and threats) and extends the limits of decision making. Stakeholder opportunities need to be retained and encouraged, and harmonized ones can work to increase the opportunity component, and threaten or replace, or reduce their threats and opportunities. Each stakeholder has $r$ her own level of influence on the project, the greater the impact on the casual stakeholder is, the better, and for the threatened stakeholder, on the contrary: a high impact can lead to a deterioration in project results.

Conclusions. Wind power development is one of the most promising areas of economic security, energy independence and the environment for any country. Skillful management that takes into account the specific WPP, the uncertainties of the internal and external environment, could balance the value orientations of all project holders and aim to improve the efficiency and effectiveness of such projects.

The article identifies the stages of risk management of WPP stakeholders, describes the mathematical model of such management, which allows them to assess their opportunities and threats, determine the magnitude of risk balances, to evaluate the stake holders on these balances and to form multiple stake holders in accordance with their balance sheets. The possible states of opportunities and threats of stakeholders are mathematically described, with the likely values of risk balances for each stakeholder in wind power projects, determined by the expert method through expert interviews. It is determined that, according to the state of the system of interaction of opportunities and threats of WPP stakeholders, all stakeholders can be divided into three groups: threatening, harmonized and chance. Further research should be directed toward determining the impact of risk balances on the effectiveness of WPP management within the three categories that correspond to the "magic" triangle of project management goals: duration, cost, quality and impact of the stakeholder risk balance on its individual risk tolerance.

\section{REFERENCES}

1. Bakulich, O.O., Sevostianova A.V. (2018). Problems of wind power industry in project development and management. Bulletin of the National Transport University. Technical

Sciences Series. Scientific and Technical Collection. - K.: NTU, 3 (42), 3-9.

2. Danchenko, O.B. (2014). Methods of risk management of 
alternative energy projects / Danchenko OB, Borisova NI // Collection of scientific papers "Bulletin of NTU" KPI ", Kharkov: NTU KPI, 2, 52-58.

3. Borisova, N.I. (2014). Modern methods and means of risk management in the application to the management of alternative energy projects / Borisova N.I. // Bulletin of the State Technical University: Coll. of sciences. Prospect Cherkasy: ChSTU. 2, 19-25.

4. Bakulich, O.O. (2017). Methods of project management in the field of wind power / Bakulich O.O., Sevostianova A.V. // International Scientific - Practical Conference. Economics, Business and Tourism: Challenges, Achievements and Innovations, Kutaisi, 16-19.

5. Bakulich, O. O. (2018). Analysis of information and mathematical methods of resource management in the development of wind power company projects / Bakulich O.O., Sevostianova A.V. // International scientific conference "Globalization and modern business challenges", Tbilisi, 2526.05.2018, 12-17.

6. Ostanin, V.A. (2014). Chance management and risk management as dialectical opposites of management theory / Ostanin A.V., Rozhkov Y.V. // Bulletin of KhNPP: coll. scientific slave. - Khabarovsk: KhGAEP, 6 (74), 4-12.

7. PMBOK_Guide_6th_Russian [Electronic resource]. - Access mode: http://www.studfiles.ru/preview/1811796/ - Title. from the screen.
8. IPMA (2015) Individual Competence Baseline (ICB) Version 4.0 for Project, Program \& Portfolio Management // IPMA, $431 \quad$ - URL: http://products.ipma.world/ipmaproduct/icb/read-icb/.

9. Methods of management and cooperation with stakeholders. [Electronic resource] - Access mode: http://www.belerp.com/modules.php?name=Pages\&pa=show page\&pid $=158$ - Title from the screen.

10. Y.Y. Guseva (2018). Dynamic Analysis of Project Stakeholder Management Methods and Tools / Guseva Y.Y., Martynenko A.S., Chumachenko I.V. // Management of development of complex systems, 34, 27 - 36.

11. Glossary of PRINCE2 Terms [Electronic resource] - Access mode: http://megapolis-profi.ru/d/150939/d/ru__prince2_glossary_of_terms_v1.3_-_russian-english_1.pdf

12. A.V. Chmut (2017). Harmonization of interests of shareholders of corporations and other stakeholders in terms of entering international markets / Chmut A.V., Fedorova T.V. // Manager. Of Donetsk State University of Management, 2 (75), 91-97.

13. Bakulich, O.O., Sevostianova A.V. (2019). A conceptual model of balance of risks (opportunities and threats) of stakeholders in wind power projects. Academic notes of KROK University: Collection. Sciences. BC - Kiev: Univ. "KROK", 3 (55), 19-25. 